\title{
Sero-prevalence of Human Immunodeficiency Virus in ophthalmic surgical patients in Uyo, South-South Nigeria.
}

\author{
Abraham Emem Godwin ${ }^{1}$, Akpan Sylvia IquoAbasi ${ }^{1}$, Megbelayin Olu \\ Emmanuel $^{1}$ \\ ${ }^{I}$ Department of Ophthalmology, University of Uyo Teaching Hospital, Uyo, Akwa-Ibom State, Nigeria.
}

\begin{abstract}
Aim: To determine the prevalence of human immunodeficiency virus (HIV) among patients who underwent eye surgery in a tertiary facility. Materials and methods: This was a retrospective study using health records of patients who underwent eye surgery over a $2^{1 / 2}$ year period. Demographic information including age, sex, occupation, diagnosis, type of surgery and HIV status were extracted and analyzed with SPSS 17.0. Results: A total of 99 patients were screened, made up of 60 males and 39 females. The age range was between 5 and 83 years with mean age of 49.9 years. Seven patients $(7.1 \%)$ were sero-positive for human immunodeficiency virus. Of these, five were between $3^{\text {rd }}$ and $5^{\text {th }}$ decade of life while 2 were more than sixty years old. Conclusion: The sero-prevalence of HIV is high in our series. Patients undergoing ophthalmic surgery should be counseled to accept pre-operative HIV screening and ophthalmic surgeons should take precautions to minimize the risks of transmission to self, other health workers and uninfected patients.
\end{abstract}

Keywords: Sero-prevalence, HIV, ophthalmic, surgical, patients.

\section{Introduction}

The Human Immune Deficiency Virus (HIV) may have had its origins in Africa with a large percentage of those infected living in sub-Saharan Africa. ${ }^{1,2}$ HIV is thought to have started and spread unnoticed through the 1960s and 1970s, developing into epidemic proportions in the 1980s. ${ }^{1,3}$ The HIV/AIDs pandemic is currently a global phenomenon that has especially impacted on sub-Saharan Africans because of large numbers of those affected coupled with poverty and illiteracy.,

Infection with HIV and Acquired Immuno-deficiency Disease (AIDs) are among the most difficult challenges facing surgeons worldwide. Surgeons are at risk of occupationally acquired infection as a result of intimate contact with the blood and other body fluids of HIV patients requiring surgery. ${ }^{6} \mathrm{HIV}$ has been isolated from the tear fluid and conjunctiva of HIV positive but asymptomatic individuals. ${ }^{7}$ The conjunctiva and cornea are also recognized as a potential route of transmission of infection. ${ }^{8}$

The sero-positive status of the majority of the HIV positive patients may be unsuspected by the attending medical personnel who as a result, may not apply universal infection-control measures. A literature review by Veenken et al reported 33 health care workers contracted HIV infection due to their occupation. ${ }^{9}$ The risk of HIV transmission from patient to the surgeon depends on the prevalence of HIV/AIDS in the population served by the surgeon and the frequency of accidental injuries with exposure to infected blood or body fluids. Other identified factors are availability of HIV test and post-exposure prophylaxis in the institution in which the surgeon works, and importantly, compliance of the surgeon to Post Exposure Prophylaxis (PEP). ${ }^{1}$

The purpose of this study was to retrospectively determine the prevalence of HIV sero-positivity among ophthalmic surgical patients in University of Uyo Teaching Hospital over two and half years.

\section{Methodology}

It was a retrospective study. Health records of patients who underwent eye surgeries between January 2011 and June 2013 were reviewed. Demographic information including age, sex, occupation, diagnosis, type of surgery and HIV status were extracted and analyzed using SPSS 17.0. Minor procedures such as superficial corneal foreign body removal, epilation etc carried out in the treatment room located in the out-patient clinic were excluded from our study.

\section{Result}

Of the 99 patients analyzed, 60 were males and 39 were females with a male to female ratio of 1:0.65. The age range was 5 to 83 years with a mean age of $49.9 \pm 3.17$ years (table 1$)$. Seven patients $(7.1 \%)$ were seropositive for HIV, of which $5(71.4 \%)$ were between $3^{\text {rd }}$ and $5^{\text {th }}$ decade of life while $2(28.6 \%)$ were older than sixty years. Of the 7 sero-positive patients, $4(57 \%)$ were males and $3(43 \%)$ were females. Uncorrected visual acuity ranged from $6 / 6$ to No Perception of Light. There was no association between patients' HIV status and $\operatorname{sex}\left(\mathrm{X}^{2}=0.355, \mathrm{p}=0.837\right)$. The association between patients' occupation and HIV status was not 
Sero-prevalence of Human Immunodeficiency Virus in ophthalmic surgical patients in Uyo, South-

statistically significant $\left(\mathrm{X}^{2}=24.866, \mathrm{p}=0.72\right)$. Table 2 shows distribution of HIV seropositivity in relation to surgical procedures. Table 3 shows patients' occupation and figure 1 shows indications for surgical interventions.

TABLE 1: AGE DISTRIBUTION

\begin{tabular}{|c|c|c|}
\hline \\
\hline AGE GROUP & FREQUENCY & PERCENTAGE \\
\hline$<10$ & 6 & 6.1 \\
\hline 11-20 & 5 & 5.1 \\
\hline $21-30$ & 13 & 13.1 \\
\hline $31-40$ & 12 & 12.1 \\
\hline $41-50$ & 19 & 19.2 \\
\hline $51-60$ & 21 & 21.2 \\
\hline 61-70 & 16 & 16.2 \\
\hline $71-80$ & 5 & 5.1 \\
\hline $81-90$ & 2 & 2.0 \\
\hline Total & 99 & 100.0 \\
\hline \multicolumn{3}{|c|}{ TABLE 2: OCCUPATION } \\
\hline OCCUPATION & FREQ & PER CENTAGE \\
\hline Civil servant & 17 & 17.2 \\
\hline Trader & 24 & 24.2 \\
\hline Farmer & 10 & 10.1 \\
\hline Student/pupil & 15 & 15.2 \\
\hline Pensioner/dependant/house wife & 14 & 14.1 \\
\hline Artisan & 15 & 15.2 \\
\hline Village head & 1 & 1.0 \\
\hline Business & 3 & 3.0 \\
\hline Total & 99 & 100 \\
\hline
\end{tabular}

TABLE 3: DISTRIBUTION OF HIV STATUS AND SURGICAL PROCEDURES

\begin{tabular}{lll}
\hline Surgery & Frequency & Percent \\
\hline Exploration/repair & 2 & 28.6 \\
Cataract & 1 & 14.3 \\
Excisional biopsy & 1 & 14.3 \\
Pterygium & 1 & 14.3 \\
Evisceration/Enucleation & 1 & 14.3 \\
Others & 1 & 14.3 \\
Incision and curettage & 0 & 0 \\
Total & $\mathbf{7}$ & $\mathbf{1 0 0}$ \\
\hline
\end{tabular}




\section{FIGURE 1: SURGICAL PROCEDURES}

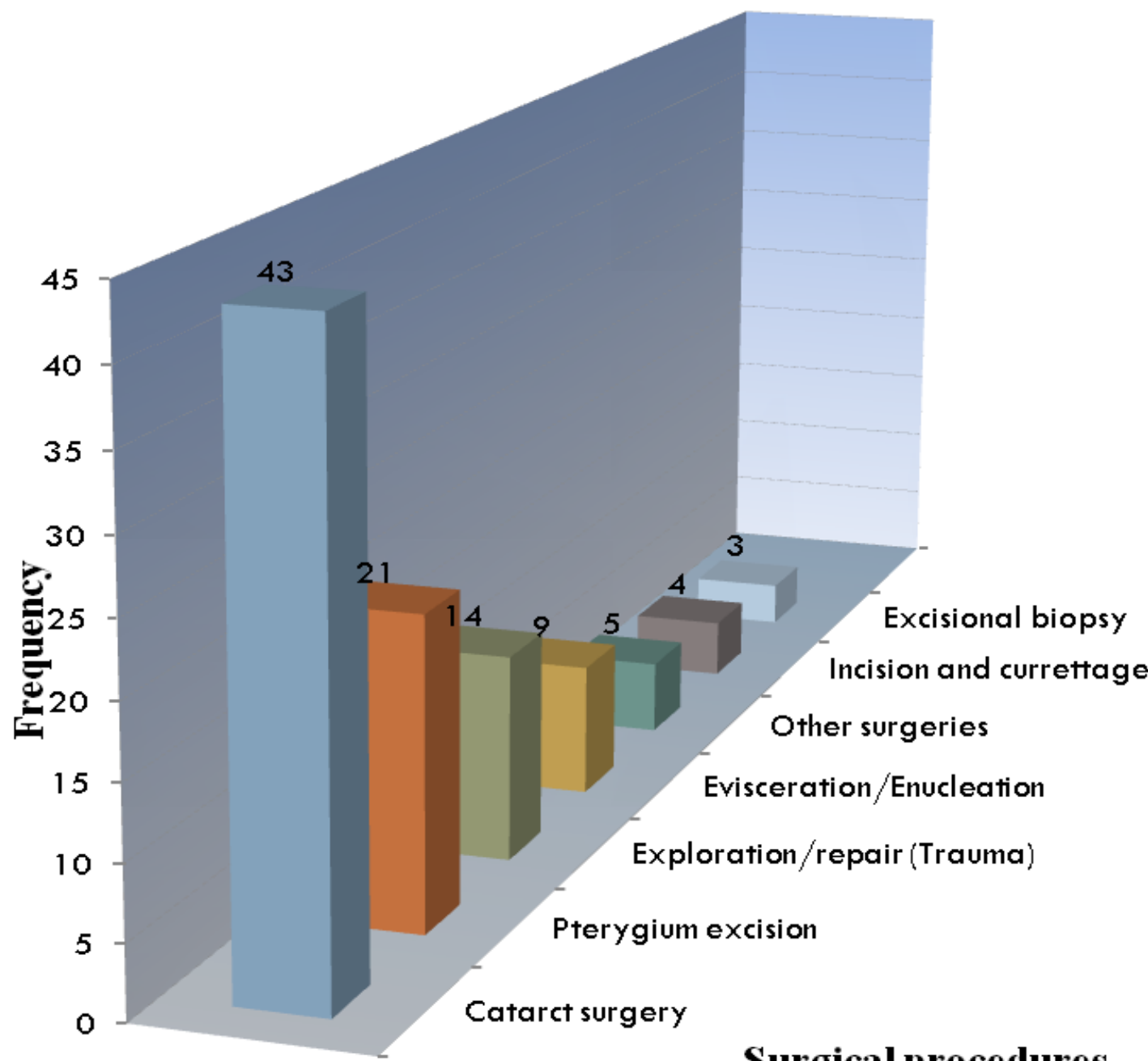

\section{Surgical procedures}

\section{Discussion}

The high prevalence rate $(7.1 \%)$ recorded in our study concurred with the other findings in sub-Saharan Africa. ${ }^{10-12}$ Similar studies on ophthalmic surgical patients at Ohaozara, Enugu and Benin-City found prevalence rates of $3.7 \%, 3 \%$ and $2.6 \%$ respectively. ${ }^{13-15}$ Odugu et $\mathrm{al}^{16}$ reported a high prevalence figure of $7.31 \%$ among ophthalmic surgical patients in a Niger-Delta community, the same geographical region our study was conducted. Niger-Delta bears much of Nigeria's HIV burden, possibly arising from the huge economic activities of oil exploration and influx of different categories of people into the area. The high prevalence figure of our study could also be attributable to our service catchment areas with our clientele extending far beyond our locality to neighbouring states.

Over $70 \%$ of seropositive patients were below 60 years, a trend reported by other Nigeria studies. ${ }^{12,15,17}$ Inconsistences have been noticed in the gender distribution of HIV among ophthalmic surgical patients. In our cohorts, male dominated similar to reports from Osogbo, Osun state. ${ }^{12}$ Perhaps owing to stronger economic strength than their female counterparts in our environment, men are more likely to afford and present for surgical treatment than females. In a rural surgical outfit in Ohaozara, Ebonyi state, where ophthalmic surgical services may have been subsidized or rendered free, Okoye et $\mathrm{al}^{15}$ reported higher female prevalence.

Type of occupation has been linked with HIV prevalence. ${ }^{9}$ The current study did not find association between occupation and HIV prevalence. This is possibly due to its relatively small, non-representative data coupled with the inherent bias of a hospital-based study like ours.

It is concluded from this study that routine HIV screening following adequate pre-screening counseling appears justifiable before ophthalmic surgery, at least in areas known for high prevalence of the disease. This is 
to ensure extra precautions by the surgeons and prompt interventional measures for the newly diagnosed HIV patients. The retrospective nature of this study which did not allow us to include other informative parameters was an acknowledged limitation of the study. For instance, confirmatory test using immunocomb II HIV 1 and 2 could not be carried out. Our study was conducted in a federal tertiary referral centre, thus requiring cautious extrapolations to other nonsimilar ophthalmic surgical outfits. In establishing an unremitting high prevalence of HIV among ophthalmic surgical patients, however, this study has achieved its purpose.

\section{Acknowledgement}

The hospital's health record staff and ophthalmology resident doctors are hereby acknowledged for their invaluable contributions.

\section{References}

[1]. Peter M. Nthumba and Paul I. Juma Kijabe. HIV Infection: Implications on Surgical Practice. in Eugenia Barros (ed). HIV Infection- Impact, Awareness and Social Implications of living with HIV/AIDS., (Nairob: Kenya, 2011), 271-284.

[2]. Nwosu SNN, Anyiwo CE, OnochieAU. The Seroprevalenve of Human Immunodeficiency in Nigerians with Ophthalmic Disorders. Nig J Ophthalmo 1996, 4, 9-11.

[3]. Kehinde AV, Samaila E, Eni RN. Ocular aids: experience at the Guinness Ophthalmic unit,Kaduna , Nigeria. Niger J Surg Res 2005; (7)3: 305-308.

[4]. Mann J. Control Strategies: AIDS a Global problem. AIDS action, 1986, 1,4-5

[5]. Lewallen S. HIV/AIDS: What is the impact on prevention of blindness programmes? Community Eye Health, 2003, 16, 33- 34

[6]. Olapade-Olaopa EO, Salami MA, Afolabi AO. HIV/AIDS and the surgeon. Afr J Med Sci, 2006, 35, 77-83.

[7]. WHO report. Guidelines on sterilization and high - level disinfections methods effective against human immunodeficiency virus (HIV). AIDS Action 1988, 3 (suppl), 2 - 4

[8]. Marasco S, Woods S. The risk of eye splash injuries in surgery. Aust N Z J Surg, 1995, 65, 627-629

[9]. Veeken H, Verbeek J, Houweling H, Cobelens F. Occupational HIV infection and Health care workers in the tropics. Trop Doc, $1991,21,28-31$

[10]. UNAIDS Reports on the Global AIDS 2006: HIV/AIDS estimates and data. 2005.

[11]. Offor E, Unuigbe E, Ogbeide O. Adolescent and HIV/AIDS: an update of cases seen in Benin City, Nigeria. JMBR, 2002, 1, 59-62.

[12]. Adeoti CO, Fagbami AA, Isawumi MA. Human Immunodeficiency Virus (HIV) seropositivity in patients presenting to an eye clinic. Ann Afri Med, 2005, (4)2, 92.

[13]. Ukponmwan CU, Egbagbe EE, Osahon AI. Prevalence of Human Immunodeficiecy virus in ophthalmic surgical patients. Niger J Clin Pract, 2009, 12:,120-123

[14]. Ezegwui IR, AkaraiweNN, Onwasigwe EN. Seroprevalence of HIV among ophthalmic surgery patients at ESUT Teaching Hospital, Parklane, Enugu, Proc of Annual Congress of Ophthalmolgical Society of Nigeria, Enugu, 2007, 47-48.

[15]. Okoye O, Magulike N, Chuka-Okosa, C. Prevalence of Human Immunodeficiency Virus Seropositivity among Eye Surgical Patients at a Rural Eye Care Facility in South-Eastern Nigeria. Middle East Afr J Ophthalmol, 2012, 19(1), 93-96.

[16]. Odugu K, Mercieca K, Thampy R, Fiebai B. HIV seroprevalence in patients undergoing ophthalmic surgery in Niger-Delta region in Nigeria. Niger J Optthalmol, 2008, 16, 36-38.

[17]. Nwosu SN. HIV/AIDS in ophthalmic patients: The Guinness Eye Centre, Onitsha experience. Niger Postgrad Med J, 2008, 15, 2427. 